\title{
Quality of Life (QoL) assessment in a cohort of patients with Phenylketonuria
}

\author{
Chiara Cazzorla', Luca Cegolon, ${ }^{2,3}$, Alessandro P Burlina ${ }^{4}$, Andrea Celato ${ }^{1}$, Pamela Massa ${ }^{1}$, Laura Giordano ${ }^{1}$, \\ Giulia Polo ${ }^{1}$, Aurora Daniele ${ }^{5,6}$, Francesco Salvatore ${ }^{6,7}$ and Alberto B Burlina ${ }^{1^{*}}$
}

\begin{abstract}
Background: Phenylketonuria (PKU) is a chronic inborn error of amino acid metabolism that requires lifelong follow-up and intervention, which may represent strains on Quality of Life (QoL). This observational study evaluated QoL in a cohort of PKU patients, using updated and detailed instruments.

Methods: 22 patients with mild PKU respondent to $\mathrm{BH}_{4}$ and 21 patients with classical PKU treated with diet were recruited in this study. Adult patients completed WHOQOL questionnaire-100 (WHOQOL-100) and pediatric patients the Pediatric QoL inventory (PedsQL ${ }^{\mathrm{TM}}$ ). Psychiatric and mood disorders were also evaluated using TAD or BDI and STAI-Y inventories. A multivariable linear regression model was fitted to investigate the predictors of QoL, including age, sex, treatment type, length of current treatment, educational level and employment status (only for adults) as covariates. Results were presented as regression coefficients with 95\% confidence interval.

Results: Global QoL scores were within normal range both in patients with mild and classical disease but global QoL scores were significantly higher in patients with mild PKU under $\mathrm{BH}_{4}$ treatment as compared to those affected by classical disease who were under diet regimen. Furthermore, QoL significantly increased in long treated PKU patients. Among adult patients, QoL scores were significantly lower in males, in patients with lower education and in those employed or unemployed as compared to students (baseline).

Conclusions: Both diet and medical treatment based upon $\mathrm{BH}_{4}$ seem to be associated with higher QoL in the long run. However, patients with mild PKU can rely on $\mathrm{BH}_{4}$ to achieve a higher Phe tolerance and a better compliance to therapy due to diet relaxation/avoidance. Some specific categories of patients with a lower QoL should be investigated more in depth, engaging with those at risk of lower treatment compliance. The questionnaires employed in the present study seemed to be able to effectively detect criticalities in QoL assessment and represent an advance from previous inventories employed in the past.
\end{abstract}

Keywords: Phenylketonuria, Tetrahydrobiopterin, Quality of life, Word Health Organization Quality Of Life questionnaire-100

\section{Background}

Phenylketonuria (PKU, OMIM 261600) is a complex autosomal recessive metabolic disorder caused by mutations of the gene encoding for phenylalanine hydroxylase enzyme (PAH, EC 1.14.16.1). PAH deficiency leads to an accumulation of phenylalanine (Phe) in blood and brain that gradually impairs metabolic functioning and cognitive development [1]. PAH is mainly active in the liver and

\footnotetext{
* Correspondence: alberto.burlina@unipd.it

'Division of Inborn Metabolic Diseases, Department of Pediatrics, Padua University Hospital, Padua, Italy

Full list of author information is available at the end of the article
}

requires $6 \mathrm{R}$-tetrahydrobiopterin $\left(\mathrm{BH}_{4}\right)$ as a critical cofactor. An early dietary intervention based on a Phe restricted diet and the supplementation of an amino acids mixture is able to keep Phe blood levels low, avoiding mental retardation or neurological abnormalities that have been described in untreated patients [2]. Diet should be maintained lifelong and this requires a lot of effort, especially in adulthood, owing to the growing instances of social relationships [3-5]. Indeed, PKU patients must go through frequent biochemical controls, several dietary assessments and adjustments that represent stressors for both adolescent and adult patients [6,7]. Furthermore, in young 
adults, the strict adherence to diet may lead to some difficulties in building up good social relationships [8], often resulting in poor adherence to dietary regimen with risks of cognitive, neuropsychological and behavioural impairment $[9,10] . \mathrm{BH}_{4}$ has been introduced since 1999 as a therapeutic option alternative to diet to manage PKU, thus widely changing the matter $[7,11]$. In PKU responsive patients, $\mathrm{BH}_{4}$ indeed allows to maintain a significantly low level of blood Phe, despite remarkable relaxation of dietary regimen [12,13]. Current guidelines suggest that a trial with sapropterin can be provided to all PKU patients [13], nevertheless patients with milder forms of the disease are more likely to benefit from $\mathrm{BH}_{4}$ treatment than classical ones.

In recent years there has been increasing attention on the effect of $\mathrm{BH}_{4}$ on the Quality of Life (QoL) of PKU patients previously receiving dietary intervention [14-16]. However QoL scores of PKU patients and their parents measured by current inventories are reported to be generally similar to healthy controls' $[14,17,18]$, probably as the questionnaires are not able to outline differences or criticalities expected in a chronic disease. Demirdas et al. and Ziesch et al. [14,16], for instance, investigated QoL of PKU patients using several instruments, before and after the introduction of $\mathrm{BH}_{4}$ [19]. Their results showed that:

a) QoL global scores were comparable to the ones of general population;

b) QoL scores did not improve after $\mathrm{BH}_{4}$ administration and consequential relaxation of diet.

The authors attributed their findings to several reasons:

- global QoL scores reflect a true picture;

- results are the consequence of a hidden disability hard to capture;

- QoL instruments are not enough sensitive to detect differences;

- sample of patients is underpowered;

- period of treatment is too short to reveal long term changes.

Therefore more appropriate instruments to evaluate QoL of PKU patients seems to be required.

WHOQOL-100 [20] and PedsQL are two questionnaires recently devised to better evaluate QoL as compared to previous instruments.

In view of the above, the present study aimed to assess WHOQOL-100 and PedsQL questionnaires to score personal and parental perception of QoL in a sample of PKU patients affected by mild and classical PKU. Indeed, QoL of patients with mild and classical PKU have never been compared using up-to-date instruments thus far.

\section{Methods}

\section{Study planning and sample portrayal}

This study was conducted from March 2012 till July 2012, as a result of the collaboration of Padua University Hospital (enrolling pediatric patients) with the Neurological Unit of St. Bassiano Hospital in Bassano del Grappa (enrolling adult patients). The study protocol followed the principles of the Declaration of Helsinki and ICH/GCP and was approved by the Ethical committee of the Padua University Hospital. All recruited patients and/or their respective parents signed an informed consent.

A total of 30 mild $\mathrm{BH}_{4}$ potentially respondent patients have been selected to participate to the study. 3 of them were excluded due to age criteria (patients under 4 years of age), 2 were excluded due to the presence of mental impairment and 3 did not give their consent to participate to the study. An almost identical number of classical PKU patients were then recruited considering gender, disease severity and age-matching criteria.

Thus $22 \mathrm{BH}_{4}$ responsive patients affected by mild PKU and 21 classical PKU patients treated with diet were recruited in this study. Information on age (in years), gender, treatment type $\left(\mathrm{BH}_{4}\right.$ vs. diet), treatment length (months of current treatment, diet or $\mathrm{BH}_{4}$ therapy), employment status of adult patients (student, employed, unemployed) and educational level of pediatric (nursery, primary school, junior secondary school) or adult patients (secondary school or post-graduate education) were collected.

Patients affected by mild PKU treated with $\mathrm{BH}_{4}$ were included if:

- PKU was diagnosed by neonatal screening;

- Phe blood level ranged between 600 and $1200 \mu \mathrm{mol} / \mathrm{L}$;

- a significant decrease of blood Phe level (>30\%) following a $\mathrm{BH}_{4}$ loading test (performed with a $\mathrm{BH}_{4}$ dosage of $20 \mathrm{mg} / \mathrm{kg} /$ day).

Genetic analysis was conducted in all patients (both in mild PKU patients treated with $\mathrm{BH}_{4}$ as well as in classical PKU patients on diet). All patients with mild PKU were, thereafter, treated with a $\mathrm{BH}_{4}$ dosage of $10 \mathrm{mg} / \mathrm{Kg} /$ day, as suggested by Kure et al. [11], for a time period of 1 to 11 years. Until $2009 \mathrm{BH}_{4}$ was provided by Schircks Laboratories in Switzerland; subsequently there was a switch to sapropterin dihydrochloride (Kuvan ${ }^{\circ}$, Merck Serono, Germany). All patients on $\mathrm{BH}_{4} /$ sapropterin treatment were allowed a relevant relaxation of the dietary restriction [21].

Analysis of Phe was performed using liquid chromatography/tandem mass spectrometry (CC-MS/MS) as previously described [22]. 


\section{Technical instruments and questionnaires}

A general instrument for QoL perception was administered to all study subjects.

In detail, for pediatric patients (6-16 years old) the Pediatric Quality of Life Inventory, PedsQL, was employed, an instrument measuring several aspects of QoL including a child self-report and a parent proxy-report format [23].

PedsQL consists of Likert scale items and yields a score scale for Physical Functioning, Emotional Functioning, School Functioning and Social Functioning. Items are reverse-scored and linearly transformed in a 0-100 scale, with higher scores corresponding to higher QoL. The PedsQL was self-administered for children 8-16 years old and by parents and administered by an interviewer to children 6-7 years old. In order to analyse the participants' scores (children and their respective parents), results were compared with age-matched normative data controls taken from literature [24]. The Test of Anxiety and Depression in Infancy and Adolescence, TAD, was also used, an inventory including a self and a proxy-report [25]. This instrument enables to investigate the symptoms associated with anxiety and depression.

For adult patients (18-35 years old) the World Health Organization QoL score (WHOQOL-100) was employed, recording the global perception of their own QoL [20]. Items are linearly transformed into a 4-20 scale, with higher scores corresponding to higher QoL. This instrument was previously used also to test QoL in patients with other inherited metabolic diseases [8]. Age-matched normative data (age range: 18-44 years) taken from literature [26] was considered in the analysis.

The Beck Depression Inventory, BDI, a self-report instrument, which is both clinical and diagnostic, was also used to evaluate the presence and the degree of depression [27]. In this instrument the total score is compared to a reference value, to determine the severity of depression. Higher total scores are associated with more severe depressive symptoms.

Finally, the State-Trait Anxiety Inventory form $\mathrm{Y}$ (STAI-Y) was employed, an instrument which investigates the level of anxiety in adult patients. This inventory discriminate between state anxiety, for instance a transitory emotional condition, from trait anxiety, defined as a personality trait [28].

\section{Statistical analysis}

The ANOVA test was employed to compare the mean values of $\mathrm{Phe}$ of $\mathrm{BH}_{4}$ patients and patients on diet. Four univariable linear regression models were employed to assess the association between QoL and Phe levels at assessment day and over the past 12 months in both groups (mild PKU on $\mathrm{BH}_{4}$ treatment and classical patients on diet). Two separate multivariable linear regression models were set up to investigate the effect of various predictors on QoL (as continuous outcome) perceived by the patients. The first model was fitted only on pediatric PKU patients controlling for age, sex, treatment type $\left(\mathrm{BH}_{4}\right.$ vs. diet), length of current treatment (diet or $\mathrm{BH}_{4}$ ) and educational level. The second model was fitted only on adults PKU patients, controlling for age, sex, treatment type $\left(\mathrm{BH}_{4}\right.$ vs. diet), length of current treatment (diet or $\mathrm{BH}_{4}$ ), educational level and employment status. Results of all above models were expressed as regression coefficients (RC) with 95\% confidence interval (95\% CI).

The analysis was conducted with Stata 13 statistical package (Stata Corporation, College Station, Texas, USA).

\section{Results}

\section{Patient sample}

Table 1 shows the distribution of the 43 PKU patients (20 females and 23 males) aged between 6 and 35 (mean 17.1 \pm 9.0): $22 \mathrm{BH}_{4}$ responsive patients (aged between 6 and 35 years; mean $=15.4 \pm 9.5$ ) affected by mild PKU, and 21 classical PKU patients treated with diet (aged between 8 and 34 years; mean $=18.9 \pm 8.3$ ).

Patients were broken down as follows:

- a group of 26 pediatric patients aged between 6 and 16 years with their respective parents;

- a second group of 17 adult patients aged between 17 and 35 years.

Three pediatric patients (11.5\%) were attending nursery, twelve (46.2\%) attended primary school and eleven (42.3\%) attended junior secondary school. Fourteen adults patients $(82.4 \%)$ had a secondary school education and three $(17.6 \%)$ had a post-graduate education. Five adult patients $(29.4 \%)$ were students, nine $(52.9 \%)$ were employed and three (17.7\%) were unemployed.

The average length of current treatment (diet or $\mathrm{BH}_{4}$ ) was $209.65 \pm 140.02$ months. The mean QoL of pediatric patients was $79.26 \pm 82.97$, whereas in adults it was $16.47 \pm 0.51$

Tables 2 and 3 presents the biochemical, therapeutic and personal data of all patients:

- 21 classical PKU patients treated with diet alone;

- 6 adult patients treated with sapropterin alone;

- 8 patients (all pediatric patients) treated with sapropterin as well as low protein foods and natural proteins (mainly from animal sources);

- 8 patients ( 7 children and 1 adult) requiring a combined treatment of sapropterin along with Phe restricted diet and a supplementation of Phe-free amino acid compounds.

$\mathrm{BH}_{4}$ was generally well tolerated and no adverse events were reported over the years. 
Table 1 Frequency distribution of the 43 PKU patients

\begin{tabular}{|c|c|c|c|c|c|}
\hline Variables & Strata & No. (\%) & Mean \pm SD & $\begin{array}{l}\text { Mean } \pm \text { SD normative } \\
\text { population (Child Self-report) }\end{array}$ & $\begin{array}{l}\text { Mean } \pm \text { SD normative population } \\
\text { (Parent proxy-report) }\end{array}$ \\
\hline \multirow[t]{2}{*}{ Gender } & Female & $20(46.5)$ & & & \\
\hline & Male & $23(53.5)$ & & & \\
\hline Age (years) & & & $17.09 \pm 8.98$ & & \\
\hline \multirow[t]{2}{*}{ Patients } & Adult & $17(40.0)$ & & & \\
\hline & Pediatric & $26(60.0)$ & & & \\
\hline \multirow{3}{*}{$\begin{array}{l}\text { Education level } \\
\text { (pediatric patients) }\end{array}$} & Nursery & $3(11.5)$ & & & \\
\hline & Primary school & $12(46.2)$ & & & \\
\hline & $\begin{array}{l}\text { Junior secondary } \\
\text { school }\end{array}$ & $11(42.3)$ & & & \\
\hline \multirow{2}{*}{$\begin{array}{l}\text { Education level } \\
\text { (adult patients) }\end{array}$} & Secondary school & $14(82.4)$ & & & \\
\hline & Post-graduate & $3(17.6)$ & & & \\
\hline \multirow{3}{*}{$\begin{array}{l}\text { Employment status } \\
\text { (adult patients) }\end{array}$} & Student & $5(29.4)$ & & & \\
\hline & Employed & $9(52.9)$ & & & \\
\hline & Unemployed & $3(17.7)$ & & & \\
\hline \multirow[t]{2}{*}{ Treatment type } & Diet & $21(48.8)$ & & & \\
\hline & $\mathrm{BH}_{4}$ & $22(51.2)$ & & & \\
\hline Treatment length (months) & & & $209.65 \pm 140.02$ & & \\
\hline QoL pediatric (range: 0-100) & & & $79.26 \pm 82.97$ & $79,37 \pm 10[24]$ & $81,74 \pm 11,21[24]$ \\
\hline QoL adults (range: 4-20) & & & $16.47 \pm 0.51$ & $14,9 \pm 2,9[26]$ & \\
\hline
\end{tabular}

Number (No.), percentage (\%), mean and standard deviation (SD).

Genetic analysis showed previously described $\mathrm{BH}_{4}$ responsive variants $[15,19,29-35]$ of $\mathrm{PAH}$ gene and previously known classical PKU variants [36].

\section{Blood Phe levels}

Blood Phe concentrations of all patients on $\mathrm{BH}_{4}$ treatment were within the therapeutic range both on the day of assessment and over the course of previous 12 months, in compliance with the Italian guidelines (0-12 years range: 120-360 $\mu \mathrm{mol} / \mathrm{L}$; >13 years range: $120-600 \mu \mathrm{mol} / \mathrm{L}$ ) [13]. Phe tolerance increased 2-4 times above normal values following $\mathrm{BH}_{4}$ treatment [21].

Tables 2 and 3 shows that the mean blood Phe concentration in pediatric patients on diet regimen fell within the borderline range both on the day of assessment $($ mean $=357 \pm 150 \mu \mathrm{mol} / \mathrm{L})$ and over the course of previous 12 months $($ mean $=359 \pm 131 \mu \mathrm{mol} / \mathrm{L})$.

The mean blood Phe concentration in adult patients on diet regimen was above the recommended upper limit both on the day of assessment (mean $=826 \pm$ $261 \mu \mathrm{mol} / \mathrm{L}$ ) and over the course of previous 12 months $($ mean $=777 \pm 240 \mu \mathrm{mol} / \mathrm{L})$.

The mean Phe levels of mild PKU patients on $\mathrm{BH}_{4}$ were significantly lower than classical PKU patients on diet (Table 4).

Finally, QoL of both groups (mild PKU patients on $\mathrm{BH} 4$ and classical PKU patients on diet) was significantly correlated with the average value of Phe over the previous 12 months and Phe value measured on the day of assessment (see Table 5).

\section{Quality of life}

Parents' perception of patients QoL showed no significant mean differences as compared to normative children's data. Moreover, patients' perception of QoL did not significantly differ from normative data. There was no statistically significant correlation between parents and children perception of QoL. The trend tended towards 0 in every instrument observed (Correlation Coefficient $=0.148, \mathrm{p}>0.05$ ).

As it can be seen from Table 6, after holding constant the effects of all other predictors, mean QoL score in pediatric patients was significantly higher in pediatric patients with mild PKU on $\mathrm{BH}_{4}$ treatment $(\mathrm{RC}=15.12$; 95\% CI: 3.08; 27.15) as compared to pediatric patients affected by classical disease treated with diet (reference). A significantly increase of QoL $(\mathrm{RC}=0.11$; 95\% CI: $0.01 ; 0.21)$ was also observed in long treated patients (either diet or $\mathrm{BH}_{4}$ ).

Similar results were also observed for adult patients (Table 7). By holding constant the effect of other terms, mean QoL scores were indeed significantly higher in adult patients with mild $\mathrm{PKU}$ under $\mathrm{BH}_{4}$ treatment ( $\mathrm{RC}=$ 7.89; 95\% CI: 2.47; 13.31) as compared to patients with classical PKU on diet (reference). In adult patients QoL was also significantly lower in males $(\mathrm{RC}=-2.58$; $95 \% \mathrm{CI}$ : 
Table 2 Distribution of pediatric patients: sex, age, Phe levels

\begin{tabular}{|c|c|c|c|c|}
\hline \multicolumn{5}{|c|}{ Pediatric patients } \\
\hline $\begin{array}{l}\text { Pediatric } \\
\text { patients } \\
\text { on } \mathrm{BH}_{4} \\
\text { treatment* }\end{array}$ & Age & Sex & $\begin{array}{c}\text { Phe values }{ }^{a} \\
\text { on the day } \\
\text { of assessment }\end{array}$ & $\begin{array}{l}\text { Mean Phe values }{ }^{\mathrm{a}} \\
\text { over the course of } \\
\text { the previous } 12 \text { months }\end{array}$ \\
\hline 1 & 6 & $\mathrm{~F}$ & 313 & 292 \\
\hline II & 10 & M & 416 & 361 \\
\hline III & 8 & $\mathrm{~F}$ & 358 & 350 \\
\hline IV & 8 & $\mathrm{~F}$ & 326 & 250 \\
\hline v & 10 & $M$ & 373 & 254 \\
\hline VI & 10 & $\mathrm{~F}$ & 664 & 553 \\
\hline VII & 7 & $M$ & 268 & 261 \\
\hline VIII & 16 & $\mathrm{~F}$ & 189 & 256 \\
\hline IX & 6 & M & 254 & 335 \\
\hline $\mathrm{x}$ & 10 & $\mathrm{~F}$ & 222 & 224 \\
\hline XI & 6 & M & 142 & 166 \\
\hline XII & 11 & $\mathrm{~F}$ & 240 & 251 \\
\hline XIII & 16 & $\mathrm{~F}$ & 309 & 364 \\
\hline XIV & 16 & M & 251 & 268 \\
\hline$x V$ & 7 & $\mathrm{~F}$ & 259 & 271 \\
\hline $\begin{array}{l}\text { Pediatric } \\
\text { patients } \\
\text { on dietary } \\
\text { treatment } \\
\end{array}$ & Age & Sex & $\begin{array}{l}\text { Phe values }^{a} \\
\text { on the day of } \\
\text { assessment }\end{array}$ & $\begin{array}{l}\text { Mean Phe values }{ }^{\mathrm{a}} \\
\text { over the course of the } \\
\text { previous } 12 \text { months }\end{array}$ \\
\hline $\mathrm{XVI}$ & 15 & M & 471 & 318 \\
\hline XVII & 8 & M & 473 & 343 \\
\hline XVIII & 15 & $\mathrm{~F}$ & 611 & 394 \\
\hline IXX & 15 & M & 262 & 386 \\
\hline$X X$ & 8 & M & 273 & 291 \\
\hline XXI & 10 & $F$ & 396 & 320 \\
\hline XXII & 13 & $\mathrm{~F}$ & 128 & 476 \\
\hline XXIII & 13 & $F$ & 239 & 216 \\
\hline XXIV & 9 & $F$ & 288 & 321 \\
\hline$X X V$ & 16 & $F$ & 563 & 678 \\
\hline XXVI & 12 & $M$ & 254 & 206 \\
\hline
\end{tabular}

*10 mg/Kg/day for each patient.

${ }^{a}$ Expressed in $\mu \mathrm{mol} / \mathrm{L}$.

$-4.44 ;-0.72$ ) as compared to females (reference) but was higher in those with postgraduate education $(\mathrm{RC}=3.26$; $95 \% \mathrm{CI}: 1.33$; 5.18 ) as compared to patients with secondary school education (reference). Lastly, adult patients, employed $(\mathrm{RC}=-2.22 ; 95 \% \mathrm{CI}:-4.26 ;-0.18)$ or unemployed $(\mathrm{RC}=-2.73$; 95\% CI: $-4.79 ;-0.66)$, had a significantly lower average QoL scores as compared to students (reference).

\section{TAD, BDI and STAI-Y}

TAD, BDI and STAI-Y scores were within normal values in all patients and none of the estimates reached statistical significance. In particular at the TAD test:
Table 3 Distribution of adult patients: sex, age, Phe levels

\begin{tabular}{|c|c|c|c|c|}
\hline \multicolumn{5}{|c|}{ Adult patients } \\
\hline $\begin{array}{c}\text { Adults } \\
\text { patients } \\
\text { on } \mathrm{BH}_{4} \\
\text { treatment* }\end{array}$ & Age & Sex & $\begin{array}{c}\text { Phe values }{ }^{\mathrm{a}} \\
\text { on the day } \\
\text { of assessment }\end{array}$ & $\begin{array}{l}\text { Mean Phe Values }^{\mathrm{a}} \\
\text { over the course of the } \\
\text { previous } 12 \text { months }\end{array}$ \\
\hline 1 & 26 & $M$ & 273 & 255 \\
\hline II & 35 & M & 502 & 541 \\
\hline III & 30 & M & 654 & 586 \\
\hline IV & 32 & $\mathrm{~F}$ & 683 & 646 \\
\hline v & 21 & F & 652 & 666 \\
\hline VI & 18 & M & 349 & 414 \\
\hline VII & 30 & M & 236 & 195 \\
\hline $\begin{array}{c}\text { Adults } \\
\text { patients } \\
\text { on dietary } \\
\text { treatment } \\
\end{array}$ & Age & Sex & $\begin{array}{c}\text { Phe values }{ }^{\mathrm{a}} \\
\text { on the day } \\
\text { of assessment }\end{array}$ & $\begin{array}{l}\text { Mean Phe values }^{a} \\
\text { over the course of the } \\
\text { previous } 12 \text { months }\end{array}$ \\
\hline VIII & 28 & $\mathrm{~F}$ & 922 & 1032 \\
\hline IX & 27 & $\mathrm{~F}$ & 624 & 608 \\
\hline$x$ & 18 & $\mathrm{~F}$ & 635 & 557 \\
\hline$X I$ & 28 & M & 1359 & 1238 \\
\hline XII & 27 & M & 917 & 784 \\
\hline XIII & 17 & F & 481 & 442 \\
\hline XIV & 30 & M & 1120 & 950 \\
\hline$x V$ & 29 & M & 735 & 638 \\
\hline $\mathrm{XVI}$ & 34 & M & 782 & 800 \\
\hline XVII & 24 & $\mathrm{~F}$ & 682 & 719 \\
\hline
\end{tabular}

*10 mg/Kg/day for each patient.

aExressed in $\mu \mathrm{mol} / \mathrm{L}$.

- 2 parents out of 15 reported a mild level of depression in their children;

- 3 parents out of 15 reported a mild level of anxiety in their children;

- 2 parents out of 15 reported a mild level of social difficulties in their children;

- only 1 pediatric patient under $\mathrm{BH}_{4}$ treatment reported mild level of anxiety.

In the adult population, the BDI did not detect any pattern of depression whereas the STAI-Y displayed that two adults on dietary treatment reported anxiety (data not shown in any table).

\section{Discussion}

In the present study QoL was evaluated among 22 patients affected by mild PKU treated with $\mathrm{BH}_{4}$ and 21 patients with classical PKU on diet. Although QoL global scores were normal in both groups, both pediatric and adult patients affected by mild PKU treated with $\mathrm{BH}_{4}$ reported a significantly higher QoL scores than patients with classical PKU on diet. 
Table 4 ANOVA test comparing the mean Phe level of patients with classical PKU on diet and mild $\mathrm{PKU}_{\text {on }} \mathrm{BH}_{4}$

\begin{tabular}{lccc}
\hline & Mean \pm SD & RC (95\% Cl) & p value \\
\hline Classical PKU patients on diet & $579.95 \pm 315.75$ & Reference & $<0.01$ \\
Mild PKU patients on $\mathrm{BH}_{\mathbf{4}}$ & $362.09 \pm 164.36$ & $-217.86(-371.85 ;-63.87)$ & \\
\hline
\end{tabular}

Mean, standard deviation (SD), 95\% confidence interval $(95 \% \mathrm{Cl})$ and $\mathrm{p}$ value.

Nevertheless, both in the pediatric and adult groups a significant increase of QoL was observed in long treated patients, irrespective if it was diet or $\mathrm{BH}_{4}$ therapy. This finding seems to suggest that both treatments (diet or $\mathrm{BH}_{4}$ ) are effective to improve QoL of PKU patients in the long run. This could be attributable to increasing compliance to treatment over time (irrespective of treatment type).

Diet remains the mainstay for patients with classical disease, whereas those affected by mild PKU and struggling to adhere to diet regimen have the opportunity to rely on $\mathrm{BH}_{4}$ medical treatment.

Several studies support the effectiveness of $\mathrm{BH}_{4}$ in lowering blood Phe levels. However, there is lack of data for long term treated patients and the biochemical effect still does not have a clear counterpart in terms of QoL and behaviour for PKU patients on diet [15,16], whose QoL scores were reported to be similar to healthy controls $[17,37,38]$. Globally speaking, all previous studies suggested that PKU patients have QoL scores similar to the healthy populations. Only Cotugno et al. [39] reported lower parental QoL scores as compared to non-PKU patients. Gentile et al. [40] recently stated that this could be due to a sort of "hidden disability" effect, a cumulative impact of relatively subtle symptoms not easy to be detected by currently used QoL questionnaires. Nevertheless, adolescents and adult patients reported that adherence to diet is arduous [4-6,41] and diet treatment significantly limits their daily life activities.

In this study WHOQOL-100 and PedsQL were employed, two recently developed inventories to assess global QoL. In particular, WHOQOL-100 was developed to further improve QoL assessment in comparison to previous instruments, both by extending the number of the questions and by enabling cross-cultural comparisons. Previous instruments were developed based upon SF-36, a health related QoL scale encompassing objective measures in addition to perceived state [42]. Above all, in the SF-36 instrument physical health subscales refers largely to physical symptoms (such as pain, mobility, fatigue) and is probably more adequate to investigate QoL in other medical conditions. In disorders such as PKU, where physical illness is less severe than daily life limitations, other aspects of QoL may be more relevant to evaluate. Moreover, WHOQOL-100 has a good discriminatory power in its physical and independence domains [43] and includes a detailed section, under the independence domain, focused on the influence of medication and medical aids in daily life activities. In this sense, WHOQOL-100 encompasses a larger number of dimensions (level of independence, personal relationship, positive feelings, sexual activity and also dependence on medical substances/aids) that seems more suitable to better assess PKU treatment constraints.

However, in the present study parents' perception of patients' QoL showed no significant mean differences as compared to parents' of healthy children. Moreover, patients' perception of QoL did not significantly differ from normative data. Even advanced and detailed QoL instruments, as those employed in the present study, therefore are still not able to detect some criticalities in the assessment of QoL for PKU patients. Future inventories should be improved by focusing more on the perception of personal limitations and on the social implications associated with a chronic and restrictive dietary regimen.

Male gender was found to be significantly associated with lower QoL among adult patients. This evidence was never reported before in any study and deserves attention. The latter finding, not confirmed for male pediatric patients, might be explained by parental control. In this study adult students had a significantly higher QoL score than employed and unemployed patients. The impact of education and socio-economic status is indeed confirmed by the significantly higher QoL score found in adult patients with higher education in this study.

Table 5 Association between Phe levels (in the previous 12 months and at assessment) and QoL scores in mild PKU patients on $\mathrm{BH}_{4}$ treatment and classical patients on diet expressed as regression coefficients (RC) with $95 \%$ confidence intervals $(95 \% \mathrm{Cl})$ and $p$ values

\begin{tabular}{|c|c|c|c|}
\hline \multicolumn{4}{|l|}{ Mild PKU patients on $\mathrm{BH}_{4}$} \\
\hline & $\mathrm{RC}$ & $95 \% \mathrm{Cl}$ & $p$ value \\
\hline phenylalanine in previous 12 months & -0.13 & $(-0.21 ;-0.05)$ & $<0.01$ \\
\hline phenylalanine at assessment & $-0,11$ & $(-0.18 ;-0.04)$ & $<0.01$ \\
\hline \multicolumn{4}{|l|}{ Classical PKU patients on diet } \\
\hline & RC & $95 \% \mathrm{Cl}$ & $p$ value \\
\hline phenylalanine in previous 12 months & -0.08 & $(-0.12 ;-0.04)$ & $<0.01$ \\
\hline phenylalanine at assessment & -0.08 & $(-0.11 ;-0.04)$ & $<0.01$ \\
\hline
\end{tabular}


Table 6 Multivariable linear regression model for the quality of life in the $\mathbf{2 6}$ pediatric PKU patients

\begin{tabular}{|c|c|c|c|}
\hline Variables & No (\%) & $\mathrm{RC}(95 \% \mathrm{Cl})$ & $\mathrm{p}$ value \\
\hline \multicolumn{4}{|l|}{ Gender } \\
\hline Female & $12(46.2)$ & Reference & 0.66 \\
\hline Male & $14(53.8)$ & $-1.59(-8.91 ; 5.74)$ & \\
\hline \multicolumn{4}{|l|}{ Age (years) } \\
\hline $10.81 \pm 3.51$ & & $-0.33(-2.96 ; 2.29)$ & 0.79 \\
\hline \multicolumn{4}{|l|}{ Education level } \\
\hline Nursery & $3(11.54)$ & Reference & 0.80 \\
\hline Primary school & $12(46.15)$ & $-1.79(-15.88 ; 12.31)$ & \\
\hline Junior secondary school & $11(42.31)$ & $5.96(-20.07 ; 31.98)$ & \\
\hline \multicolumn{4}{|l|}{ Treatment } \\
\hline Diet & $11(42.3)$ & Reference & 0.02 \\
\hline $\mathrm{BH} 4$ & $15(57.7)$ & $15.12(3.08 ; 27.15)$ & \\
\hline
\end{tabular}

Length of current

treatment (months)

$89.08 \pm 61.86$

$0.11(0.01 ; 0.21)$

0.03

Number (No.), percentage (\%), regression coefficients (RC) with $95 \%$ confidence intervals $(95 \% \mathrm{Cl})$ and $\mathrm{p}$ values. Model fitted on 26 complete observations.

The chronicity and complexity of the treatment makes it hard to manage PKU both for patients and parents, often engendering anxiety and fear of not being able to adequately control the course of the disease [18]. Also, parental mental reaction certainly has an impact on

Table 7 Multivariable linear regression model for the quality of life in the $\mathbf{1 7}$ adult patients

\begin{tabular}{|c|c|c|c|}
\hline Variables & No. (\%) & RC (95\% Cl) & $p$ value \\
\hline \multicolumn{4}{|l|}{ Gender } \\
\hline Female & $8(47.1)$ & Reference & 0.01 \\
\hline Male & $9(52.9)$ & $-2.58(-4.44 ;-0.72)$ & \\
\hline \multicolumn{4}{|l|}{ Age (years) } \\
\hline $26.71 \pm 5.46$ & & $-0.16(-0.33 ; 0.02)$ & 0.08 \\
\hline \multicolumn{4}{|l|}{ Education level } \\
\hline Secondary School & $14(82.4)$ & Reference & $<0.01$ \\
\hline Post-graduate & $3(17.6)$ & $3.26(1.33 ; 5.18)$ & \\
\hline \multicolumn{4}{|l|}{ Employment status } \\
\hline Student & $5(29.4)$ & Reference & 0.01 \\
\hline Employed & $9(52.9)$ & $-2.22(-4.26 ;-0.18)$ & \\
\hline Unemployed & $3(17.7)$ & $-2.73(-4.79 ;-0.66)$ & \\
\hline \multicolumn{4}{|l|}{ Treatment } \\
\hline Diet & $10(58.8)$ & Reference & 0.01 \\
\hline $\mathrm{BH}_{4}$ & $7(41.2)$ & $7.89(2.47 ; 13.31)$ & \\
\hline \multicolumn{4}{|l|}{$\begin{array}{l}\text { Length of current } \\
\text { treatment (months) }\end{array}$} \\
\hline $209.65 \pm 140.02$ & & $0.03(0.01 ; 0.21)$ & 0.01 \\
\hline
\end{tabular}

Number (No.), percentage (\%), regression coefficients (RC) with $95 \%$ confidence intervals $(95 \% \mathrm{Cl})$ and $\mathrm{p}$ values. Model fitted on 17 complete observations. children's emotional development $[44,45]$. In addition, high levels of stress are related to the burden of treatment management, with a subsequent increased risk of depression and anxiety $[9,46]$. Indeed internalizing psychiatric disorders such as anxiety and depression have been frequently described in association with PKU [46]. In the present study BDI, TAD and STAI-Y were also administered, questionnaires never previously used to evaluate PKU patients. In terms of psychiatric symptoms, no patients scored for depression. By contrast, one patient reported mild levels of anxiety.

Several previous studies have focused on behavioural, psychiatric and social functioning in PKU patients $[9,40,46]$ with controversial results [47-49]. Although it is not possible to depict a clear psychological phenotype, internalizing traits (such as depressed mood, phobias and anxiety) have been frequently described, mostly in adult women. The results of this study confirmed that some PKU patients presented internalizing personality traits (predominantly anxiety maladaption) hard to define by currently used psychiatric inventories.

From a biochemical perspective, mild PKU patients on $\mathrm{BH}_{4}$ treatment showed better metabolic control, with lower mean blood Phe levels and lower variability towards mean values (lower $\mathrm{SD}$ ). When compared with QoL scores, Phe level was significantly correlated with QoL in both groups, at assessment as well as over the course of previous 12 months.

\section{Limitations}

The results of the present study should be interpreted with caution.

Although the distribution by gender ( 21 males vs. 22 females) and disease severity (22 mild vs. 21 classical) was fairly homogeneous, the age distribution of both groups (patients with mild $\mathrm{PKU}$ on $\mathrm{BH}_{4}$ and patients with classical PKU on diet) was heterogeneous.

Moreover, better QoL scores might be due to a less severe disease and a better self-assessment. On the other hand it can be argued that global QoL scores may be simply lower in patients with classical PKU as compared to those affected by mild disease, due to the burden of diet. In the present study mild PKU patients on $\mathrm{BH}_{4}$ indeed slightly differed from classical ones on diet as the former were affected by milder disease.

Despite a relatively small sample size, this work provided significant results which might contribute to assess and improve currently used inventories for the detection of QoL in PKU patients. Some statistical estimates may become significant with a larger study. Probably a multicenter study would be required to enlarge the cohort and reach stronger statistical power.

Finally, since the results come from a cross sectional study, a stronger study design is recommended to confirm the above findings. 


\section{Conclusions}

The aim of the present study was to investigate various aspects of QoL in a group of patients affected by mild and classical PKU, in relation to different treatment regimen $\left(\mathrm{BH}_{4}\right.$ vs. diet). Global QoL scores were found to be significantly higher in patients with mild PKU treated with $\mathrm{BH}_{4}$ as compared to patients with classical disease on dietary treatment, both in the adult and the pediatric group. Some specific categories of adult patients (males, those less educated and non students) reported a significantly lower QoL score and should be investigated more in depth, targeting categories patients with potential low treatment compliance. Finally, this study confirmed that currently used QoL inventories constitute a significant advance from instruments employed in the past; however further improvements of these inventories are still recommended.

\section{Abbreviations}

PKU: Phenylketonuria; PAH: Phenylalanine hydroxylase; Phe: Phenylalanine; $\mathrm{BH}_{4}$ : Tetrahydrobiopterin; QoL: Quality of Life; WHOQOL-100: Word Health Organization Quality Of Life questionnaire-100.

\section{Competing interests}

A.B.B. is a member of the Advisory Boards and received for research funding from Danone \& Merck-Serono. All other authors declared no competing interests.

\section{Authors' contributions}

$C C, L C, A P B, A B B$ and $A C$ designed the study, interpreted the data and drafted the manuscript; PM, LG and GP contributed to data collection, helped in interpreting data and in drafting the manuscript; AD and FS contributed to the interpretation of the data. Every authors gave final approval of the version to be submitted and to the revised version.

\section{Acknowledgements}

The authors would like to thank the patients, and their families for their interest and participation. This work was supported by the Cometa-A.S.M.M.E (Associazione per lo Studio delle Malattie Metaboliche Ereditarie). We also thank Claire Simco and Catherine Crowley for their assistance with manuscript preparation.

\section{Final disclosure}

No external funding was used to conduct this research.

\section{Author details \\ ${ }^{1}$ Division of Inborn Metabolic Diseases, Department of Pediatrics, Padua University Hospital, Padua, Italy. ${ }^{2}$ Department of Cardiac, Thoracic and Vascular Sciences, Padua University Hospital, Padua, Italy. ${ }^{3}$ Department of Infectious Disease Epidemiology, London School of Hygiene \& Tropical Medicine, London, UK. ${ }^{4}$ Neurological Unit, St. Bassiano Hospital, Bassano del Grappa, Italy. ${ }^{5}$ Department of Environmental Sciences, Biological and Pharmaceutical Technologies, Second University of Naples, Caserta, Italy. ${ }^{6}$ CEINGE-Biotecnologie Avanzate S.c.a.r.l., Naples, Italy. ${ }^{7}$ IRCCS \\ SDN-Foundation, Naples, Italy.}

Received: 8 August 2014 Accepted: 6 November 2014 Published: 4 December 2014

\section{References}

1. Blau N, van Spronsen FJ, Levy HL: Phenylketonuria. Lancet 2010, 376:1417-1427.

2. Feillet F, van Spronsen FJ, MacDonald A, Trefz FK, Demirkol M, Giovannini M, Bélanger-Quintana A, Blau N: Challenges and Pitfalls in the Management of Phenylketonuria. Pediatrics 2010, 126:333-341.

3. Hoeks MPA, den Heijer M, Janssen MCH: Adult issues in phenylketonuria. Neth J Med 2009, 67:2-7.
4. MacDonald A, Gokmen-Ozel H, van Rijn M, Burgard P: The reality of dietary compliance in the management of phenylketonuria. J Inherit Metab Dis 2010, 33:665-670.

5. MacDonald A: Diet and compliance in phenylketonuria. Eur J Pediatr 2000, 159:S136-S141.

6. Enns GM, Koch R, Brumm V, Blakely E, Suter R, Jurecki E: Suboptimal outcomes in patients with PKU treated early with diet alone: revisiting the evidence. Mol Genet Metab 2010, 101:99-109.

7. Vockley J, Andersson HC, Antshel KM, Braverman NE, Burton BK, Frazier DM, Mitchell J, Smith WE, Thompson BH, Berry SA: Phenylalanine hydroxylase deficiency: diagnosis and management guideline. Genet Med 2014, 16(2):188-200.

8. Cazzorla C, Del Rizzo M, Burgard P, Zanco C, Bordugo A, Burlina AB, Burlina AP: Application of the WHOQOL-100 for the assessment of quality life of adult patients with inherited metabolic diseases. Mol Genet Metab 2012, 106:25-30.

9. Bilder DA, Burton BK, Coon H, Leviton L, Ashworth J, Lundy BD, Vespa $H_{4}$ Bakian AV, Longo N: Psychiatric symptoms in adults with phenylketonuria. Mol Genet Metab 2013, 108:155-160.

10. Stemerdink BA, Kalverboer AF, van der Meere JJ, van der Molen MW, Huisman J, de Jong LW, Slijpers FM, Verkerk PH, van Spronsen FJ: Behaviour and school achievement in patients with early and continuosly treated phenylketonuria. J Inherit Metab Dis 2000, 23:548-562.

11. Kure S, Hou DC, Ohura T, Iwamoto H, Suzuki S, Sugiyama N, Sakamoto O, Fujii K, Matsubara Y, Narisawa K: Tetrahydrobiopterin-responsive phenylalanine hydroxylase deficiency. J Pediatr 1999, 135:375-381.

12. Burton BK, Adams DJ, Grange DK, Malone Jl, Jurecki E, Bausell H, Marra KD, Sprietsma L, Swan KT: Tetrahydrobiopterin therapy for phenilketonuria in infants and young children. J Pediatr 2011, 158:410-415.

13. Cunningham $A$, Bausell $H$, Brown $M$, Chapman $M$, DeFouw K, Ernst $S$, McClure J, O'Steen D, Pender A, Skrabal J, Wessel A, Jurecki E, Shediac R, Prasad S, Gillis J, Cederbaum S: Recommendations for the use of sapropterin in phenilketonuria. Mol Genet Metab 2012, 106:269-276.

14. Demirdas S, Maurice-Stam H, Boelen CCA, Hofstede FC, Janssen MCH, Langendonk JG, Mulder MF, Rubio-Gozalbo ME, van Spronsen FJ, de Vries M, Grootenhuis MA, Bosch AM: Evaluation of quality of life in PKU before and after introducing tetrahydrobiopterin ( $\mathrm{BH} 4)$; a prospective multi-center cohort study. Mol Genet Metab 2013, 110:s49-s56.

15. Keil S, Anjema K, van Spronsen FJ, Lambruschini N, Burlina A, BélangerQuintana A, Couce ML, Feillet F, Cerone R, Lotz-Havla AS, Muntau AC, Bosch AM, Meli CA, Billette de Villemeur T, Kern I, Riva E, Giovannini M, Damaj L, Leuzzi $\checkmark$, Blau N: Long-term follow-up and outcome of phenylketonuria patients on sapropterin: a retrospective study. Pediatrics 2013, 131:1881-1888.

16. Ziesch B, Weigel J, Thiele A, Mütze U, Rohde C, Ceglarek U, Thiery J, Kiess W, Beblo S: Tetrahydrobiopterin $\left(\mathrm{BH}_{4}\right)$ in PKU: effect on dietary treatment, metabolic control, and quality of life. J Inherit Metab Dis 2012, 35:983-992.

17. Bosch AM, Tybout W, van Spronsen FJ, de Valk HW, Wijburg FA, Grootenhuis MA: The course of life and quality of life of early and continuosly treated Dutch patients with phenylketonuria. J Inherit Metab Dis 2007, 30:29-34.

18. Fidika A, Salewski C, Goldbeck L: Quality of life among parents of children with phenylketonuria (PKU). Health Qual Life Outcomes 2013, 11:3-9.

19. Tansek MZ, Groselj U, Murko S, Kobe H, Lampret BR, Battelino T: Assessment of tetrahydrobiopterin (BH(4))-responsiveness and spontaneous phenylalanine reduction in a phenylalanine hydroxylase deficiency population. Mol Genet Metab 2012, 107(1-2):37-42.

20. The WHOQOL Group: The World Health Organization Quality of Life Assessment (WHOQOL): development and general psychometric properties. Soc Sci Med 1998, 46:1569-1585.

21. Burlina $\mathrm{A}, \mathrm{Blau} \mathrm{N}$ : Effect of $\mathrm{BH}_{4}$ supplementation on phenylalanine tolerance. J Inherit Metab Dis 2009, 32:40-45.

22. Chace DH, Millington DS, Terada N, Kahler SG, Roe CR, Hofman LF: Rapid diagnosis of phenylketonuria by quantitative analysis for phenylalanine and tyrosine in neonatal blood spots by tandem mass spectrometry. Clin Chem 1993, 39:66-71.

23. Varni JW, Burwinkle TM, Seid M, Skarr D: The PedsQL 4.0 as a pediatric population health measure: feasibility, reliability, and validity. Ambul Pediatr 2003, 329:41.

24. Trapanotto M, Giorgino D, Zulian F, Benini F, Varni JW: The Italian version of the PedsQL in children with rheumatic diseases. Clin Exp Rheumatol 2009, 27(2):373-380. 
25. Newcomer P, Barenbaum E, Bryant B: TAD: Test for Anxiety and Depression. Trento: Erickson Ed.; 2003.

26. De Girolamo G: WHOQOL. Salute e qualità di vita. Torino: Centro Scientifico Editore; 2004

27. Beck AT, Ward CH, Mendelson M, Mock J, Erbaugh J: An inventory for measuring depression. Arch Gen Psychiatry 1961, 4:561-71.

28. Spielberger CD: State-Trait Anxiety inventory: a comprehensive bibliography. Palo Alto, CA: Consulting psychologists press; 1984

29. Anjema K, van Rijn M, Hofstede FC, Bosch AM, Hollak CE, Rubio-Gozalbo E, deVries MC, Jannsen MC, Boelen CC, Burgerh of JG, Blau N, Heiner-Fokkema MR, van Spronsen FJ: Tetrahydrobiopterin responsiveness in phenylketonuria: prediction with the 48-hour loading test and genotype. Orphanet J Rare Dis 2013, 8(1):103.

30. Fiege $B$, Bonafé $L$, Ballhausen $D$, Baumgartner $M$, Thöny $B$, Meili $D$, Fiori $L$, Giovannini M, Blau N: Extended tetrahydrobiopterin loading test in the diagnosis of cofactor-responsive phenylketonuria: a pilot study. $\mathrm{Mol}$ Genet Metab 2005, 86(Suppl 1):S91-S95.

31. Hennermann JB, Vetter $B$, Wolf $C$, Windt $E$, Bührdel $P$, Seidel J, Mönch $E$, Kulozik AE: Phenylketonuria and hyperphenylalaninemia in eastern Germany: a characteristic molecular profile and 15 novel mutations. Hum Mutat 2000, 15(3):254-260.

32. Matalon R, Michals-Matalon K, Koch R, Grady J, Tyring S, Stevens RC: Response of patients with phenylketonuria in the US to tetrahydrobiopterin. Mol Genet Metab 2005, 86(Suppl 1):S17-S21.

33. Muntau AC, Röschinger W, Habich M, Demmelmair H, Hoffmann B, Sommerhoff CP, Roscher AA: Tetrahydrobiopterin as an alternative treatment for mild phenylketonuria. N Engl J Med 2002, 347(26):2122-2132.

34. Pérez-Duenas B, Vilaseca MA, Mas A, Lambruschini N, Artuch R, Gómez L, Pineda J, Gutiérrez A, Mila M, Campisto J: Tetrahydrobiopterin responsiveness in patients with phenylketonuria. Clin Biochem 2004, 37(12):1083-1090.

35. Rivera I, Mendes D, Afonso Â, Barroso M, Ramos R, Janeiro P, Oliveira A, Gaspar A, Tavares de Almeida I: Phenylalanine hydroxylase deficiency: molecular epidemiology and predictable BH4-responsiveness in South Portugal PKU patients. Mol Genet Metab 2011, 104(Supp I):S86-S92.

36. Zaffanello M, Zamboni G, Maselli M, Gandini A, Camilot M, Maffeis C, Burlina $A B$, Tatò $L:$ Genetic analysis carried out on blood-spots of phenylalanine hydroxylase-deficient newborns detected by Northeastern Italian neonatal screening. Genet Test 2005, 9(2):133-137.

37. Smith I, Knowles J: Behaviour in early treated phenylketonuria: a systematic review. Eur J Pediatr 2000, 159(Suppl 2):S89-S93.

38. Thimm E, Schmidt LE, Heldt K, Spiekerkoetter U: Health-related quality of life in children and adolescents with phenilketonuria: unimpaired HRQoL in patients but feared school failure in parents. J Inherit Metab Dis 2013, 36:767-772.

39. Cotugno G, Nicolò R, Cappelletti S, Goffredo BM, Dionisi-Vici C, Di Ciommo $\mathrm{V}$ : Adherence to diet and quality of life in patients with phenylketonuria. Acta Pediatr 2011, 100(8):1144-1149.

40. Gentile JK, Ten Hoedt AE, Bosch AM: Psychosocial aspects of PKU: hidden disabilities - a review. Mol Genet Metab 2010, 99:S64-S67.

41. Walter JH, White FJ, Hall SK, Mac Donald A, Rylance G, Boneh A, Francis DE, Shortland GJ, Schmidt M, Vail A: How practical are recommendations for dietary control in phenylketonuria? Lancet 2002, 6:55-57.

42. Huang IC, Wu AW, Frangakis C: Do the SF-36 and WHOQOL-BREF measure the same constructs? Evidence from the Taiwan population*. Qual Life Res 2006, 5(1):15-24.

43. Skevington SM: Measuring quality of life in Britain: introducing the WHOQOL-100. J Psychosom Res 1999, 47(5):449-459.

44. Friedman D, Holmbeck GN, Jandasek B, Zukerman J, Abad M: Parental functioning in families of preadolescents with spina bifida: longitudinal implications for child adjustement. J Fam Psychol 2004, 18:609-619.

45. Prince M, Patel V, Saxena S, Maj M, Maselko J, Phillips MR, Rahman A: No health without mental health. Lancet 2007, 370:859-877.

46. Brumm VL, Bilder D, Waisbren SE: Psychiatric symptoms and disorders in phenylketonuria. Mol Genet Metab 2010, 2010(99):S59-S63.

47. Pietz J, Fätkenheuer B, Burgard P, Armbruster M, Esser G, Schmidt H: Psychiatric disorders in adult patients with early-treated phenylketonuria. Pediatrics 1997, 99(3):345-350
48. Weglage J, Grenzenbach M, Pietsch M, Feldmann R, Linnenbank R, Denecke J, Koch HG: Behavioural and emotional problems in early-treated adolescents with phenylketonuria in comparison with diabetic patients and healthy controls. J Inherit Metab Dis 2000, 23:487-496.

49. Sullivan JE: Emotional outcome of adolescents and young adults with early and continuously treated phenylketonuria. J Pediatr Psychol 2001 26(8):477-484.

doi:10.1186/1471-2458-14-1243

Cite this article as: Cazzorla et al:: Quality of Life (QoL) assessment in a cohort of patients with Phenylketonuria. BMC Public Health 2014 14:1243.

\section{Submit your next manuscript to BioMed Central and take full advantage of:}

- Convenient online submission

- Thorough peer review

- No space constraints or color figure charges

- Immediate publication on acceptance

- Inclusion in PubMed, CAS, Scopus and Google Scholar

- Research which is freely available for redistribution

Submit your manuscript at www.biomedcentral.com/submit
C) Biomed Central 